\title{
Analysis of Mitochondrial DNA Control Region D-Loop in Gliomas: Result of 52 Patients
}

\author{
Sirin K. YUKSEL' ${ }^{1}$, Koray OZDUMAN²${ }^{2}$, Engin YILMAZ ${ }^{3}$ M. Necmettin PAMIR ${ }^{2}$, Cemaliye B. AKYERLI ${ }^{3}$ \\ ${ }^{1}$ Acibadem Mehmet Ali Aydinlar University, Faculty of Arts and Sciences, Department of Molecular Biology and Genetics, Istanbul, Turkey \\ ${ }^{2}$ Acibadem Mehmet Ali Aydinlar University, School of Medicine, Department of Neurosurgery, Istanbul, Turkey \\ ${ }^{3}$ Acibadem Mehmet Ali Aydinlar University, School of Medicine, Department of Medical Biology, Istanbul, Turkey
}

Corresponding author: Cemaliye BOYLU AKYERLI cemaliye.boylu@acibadem.edu.tr

\section{ABSTRACT}

AIM: To investigate the effect of mitochondrial DNA ( $m t D N A)$ variants mainly in D-loop on glioma biology.

MATERIAL and METHODS: Sanger sequencing of D-loop (15971-16451 bp) for 52 glioma patients was performed and the variations were statistically analyzed for gender, WHO classification, morphological grade, IDH/TERT status.

RESULTS: Total of 122 variations (51 unique) were identified in 52 patients. C16223T, T16189C, T16311C and T16126C variants were frequently detected. The total variation number was statistically non-significant among the analyzed categories. When individual variants were considered, T16311C and T16224C were statistically significant for WHO classification ( $p=0.033$ ), morphological grade $(p=0.036)$ and gender $(p=0.039)$, respectively.

CONCLUSION: Total variation number in D-loop was not found to be related with clinical variables. Our data suggests that individual variants may play a critical role in glioma biology.

KEYWORDS: D-loop, Glioma, Mitochondrial DNA, mtDNA variations, Mutations

ABBREVIATIONS: D-loop: Displacement loop, GBM: Glioblastoma, H: Heavy, IDH: Isocitrate dehydrogenase, L: Light, mtDNA: Mitochondrial DNA, ROS: Reactive oxygen species, TERT: Telomerase reverse transcriptase, WHO: World Health Organization

\section{INTRODUCTION}

G lial tumors (glioma) that are derived from neuroglial progenitor cells area heterogeneous group of neoplasms according to histological and molecular properties. They account for $27 \%$ of all primary brain tumors and $80 \%$ of malign tumors (21). The 2007 World Health Organization (WHO) classification of tumors of the central nervous system which is based solely on pathological criteria (13), is no longer sufficient and developments in the field of molecular biology have necessitated an improvement in this classification. With this update (2016 WHO classification), it has been suggested that the groupings should be made according to the presence of major genetic alterations especially in oxidative stress related isocitrate dehydrogenase (IDH1 and IDH2) genes and the prognosis should be evaluated according to telomerase reverse transcriptase (TERT) promoter mutations associated with increased telomerase activity (14).

Genetic code of the cell is located in the nucleus and mitochondria. The sexually inherited nuclear genome is a very well-known information transmission system. The mitochondrial genome is extremely small compared to the nuclear genome and has matrilineal inheritance $(5,9)$. The
Sirin K. YUKSEL (10): 0000-0002-7130-2933 Koray OZDUMAN (1D): 0000-0002-3543-0401 Engin YILMAZ (D): 0000-0001-8873-7645
M. Necmettin PAMIR (1): 0000-0002-5958-8625

Cemaliye B. AKYERLI (1) : 0000-0002-7263-2969 
circular human mitochondrial genome is $16569 \mathrm{bp}$ and it harbors 37 genes and a non-coding displacement loop (D-loop). 13 of these genes are protein coding, whereas 2 codes for ribosomal RNAs and the rest 22 codes for mitochondrial tRNAs.

The most important function of mitochondria is the regulation of energy metabolism by oxidative phosphorylation. Functional mitochondria are important energetic centers and essential for energy requiring cancer cells. The commonly detected mitochondrial mutations alter the mitochondrial bioenergetic and biosynthetic state instead of inactivating the mitochondrial energy metabolism. It is also suggested that mitochondria could be important in induction and progression of cancer and also resistance to treatment (20). Therefore, we focused on the D-loop region which contains essential transcription and replication elements.

Just like nuclear genome, the mitochondrial genome has inter- and intra-human variability (polymorphisms) and is prone to mutations (20). It has recently been shown that the combination of these polymorphisms (haplogroups) directly affect cancer susceptibility (6). In addition, variations have been shown across diverse human cancers (18). However, the effect of mitochondrial-genomic diversity and mutations on glioma biology is unknown.

Even though the role of nuclear-encoded gene alterations has been well documented in brain tumor development, the involvement of the mitochondrial genome in brain tumorigenesis has not yet been fully elucidated. There are arguments suggesting the association of mitochondrial variants with cancer risk, survival rates, prognosis and response to certain therapies. These variants have been proposed as valuable prognostic markers (8). Therefore, the present study aimed to identify variations in the mtDNA control region D-loop in glioma which is a well-known hotspot region for somatic mutations in many cancer types.

\section{MATERIAL and METHODS}

Tumor samples of 52 patients $(53.9 \%$ male and $46.1 \%$ female) with a mean age of $39.8 \pm 13.7$ years were included in this study following written informed consent. $71.1 \%$ of the samples were low grade [23 grade II (62.2\%), 14 grade III (37.8\%)] whereas $15(28.9 \%)$ were high grade gliomas. There were 15 oligodendroglioma $(60 \%$ grade II, $40 \%$ grade III), 22 astrocytoma (63.6\% grade II, $36.4 \%$ grade III) and 15 glioblastoma (GBM) patients. IDH1 R132 and TERT promoter C228/C250 mutations were previously analyzed by our group (1): $36.5 \%$ of the patients only IDH-mutant, $21.1 \%$ only TERTmutant, $28.8 \%$ double-mutant and $13.5 \%$ double negative.

DNA was extracted from fresh frozen tumor tissues stored in liquid nitrogen. QIAamp DNA Mini Kit (Qiagen, USA) was used according to the manufacturer's instructions. In a preliminary study, long-range PCR was performed for 4 samples with TaKaRa LA Taq DNA Polymerase (TaKaRa Bio, USA) in two reactions using the primers MTL-F1: 5'-AAAGCACATACCAAGGCCAC-3', MTL-R1: 5'-TTGGCTCTCCTTGCAAAGTT-3' and MTL-F2: 5'-TATCCGCCATCCCATACATT-3',
MTL-R2: 5'-AATGTTGAGCCGTAGATGCC-3' as previously described (17). The amplicons were checked on $1 \%$ agarose gel and normalized to $0.2 \mathrm{ng} / \mu \mathrm{L}$ after quantification with Qubit dsDNA HS Assay Kit (Thermo Fisher, USA) on Qubit Fluorometer. Paired-end sequencing libraries were prepared using the Nextera XT DNA Library Preparation Kit (Illumina, USA) following the manufacturer's instructions and mtDNA was sequenced using Illumina MiSeq (Illumina, USA) next generation technologies. In line with our focus, variations in D-loop (16063-16400 bp) were found to be more frequent compared to other loci.

Sanger sequencing of D-loop region (15971-16451 bp) was done for confirmation and increasing patient number with MT-DLOOP1-F15971: 5'-TTAACTCCATTAGCACC-3', MTDLOOP1-R16451: 5'-GCGAGGAGAGTAGCACTCTTG-3' primers (12). PCR was carried out in a total of $25 \mu \mathrm{l}$ reaction volume, consisting of 50-100 ng DNA, 1 X Colorless GoTaq Flexi Buffer, $1.5 \mathrm{mM} \mathrm{MgCl}_{2}, 200 \mu \mathrm{M}$ dNTP, 10 pmoles of each primer and $0.8 \mathrm{U}$ GoTaq Flexi DNA polymerase (Promega, USA). Cycling conditions were an initial denaturing step at $95^{\circ} \mathrm{C}$ for $2 \mathrm{~min}$, followed by 35 cycles of denaturation at $95^{\circ} \mathrm{C}$ for $30 \mathrm{sec}$, annealing at $58^{\circ} \mathrm{C}$ for $45 \mathrm{sec}$, extension at $72^{\circ} \mathrm{C}$ for $45 \mathrm{sec}$, and a final extension at $72^{\circ} \mathrm{C}$ for $3 \mathrm{~min}$. PCR products were then purified using ExoSAP-IT kit (Affymetrix, USA) and subjected to Sanger sequencing with GenomeLab DTCS - Quick Start Kit (Beckman Coulter Life Sciences, USA) according to manufacturer's recommendations, using a total of $1 \mu \mathrm{l}$ of the purified amplicon with 20 pmoles of primer. Dye removal by ethanol precipitation was performed before the sequence reactions were loaded on Beckman Coulter GeXP Genetic Analysis System (Beckman Coulter Life Sciences, USA). Lasergene Seqman II, v5.08 (Dnastar Inc., Madison, USA) was used for sequence analysis. The revised Cambridge Reference Sequence (rCRS), GenBank number NC_021920 (15), was used as the reference genome.

Fifty two glioma patients were sequenced and the total variation number was statistically analyzed for gender, WHO classification, morphological grade, IDH/TERT status. Since the samples were not normally distributed, nonparametric tests were used to compare the differences between the independent groups (Mann-Whitney $U$ test for comparison of two groups or Kruskal-Wallis test for comparison of more than two groups). The individual variant analysis was completed by chi-square test considering the Fisher's Exact test values, since the smallest theoretical frequency is $<5$.

\section{RESULTS}

In Sanger sequencing analysis of D-loop region (15971-16451 bp) of the evaluated 52 brain tumor samples, a total of 122 variations were identified, 51 being different from each other (Table I). Mean total variation number in oligodendroglioma, astrocytoma and GBM samples were $2.13 \pm 1.96,2.23 \pm 1.72$ and $2.73 \pm 1.62$, respectively. Regarding IDH R132 mutation, mean total variations were calculated as $2.21 \pm 1.95$ in IDH1 R132 mutant and $2.61 \pm 1.61$ in IDH1 R132 wild type samples. When molecular subgroups were considered according to IDH/TERT status, mean total variation numbers were: $2.26 \pm$ 
Yuksel SK. et al: D-Loop Analysis in Gliomas

Table I: Frequencies of Mitochondrial D-Loop Variations Detected in more than One Tumor Sample

\begin{tabular}{|c|c|c|c|c|c|c|c|c|c|}
\hline Variation & $\begin{array}{l}\text { Frequency } \\
\text { (\%) }\end{array}$ & Variation & $\begin{array}{l}\text { Frequency } \\
\text { (\%) }\end{array}$ & Variation & $\begin{array}{l}\text { Frequency } \\
\text { (\%) }\end{array}$ & Variation & $\begin{array}{c}\text { Frequency } \\
\text { (\%) }\end{array}$ & Variation & $\begin{array}{c}\text { Frequency } \\
\text { (\%) }\end{array}$ \\
\hline C16223T $T^{\star \star}$ & 19.2 & C16192T & 7.7 & A16309G & 7.7 & $\mathrm{~T} 16304 \mathrm{C}^{\star *}$ & 5.8 & C16286T & 3.8 \\
\hline T16189C $C^{\star *}$ & 17.3 & T16224C & 7.7 & G16390A** & 7.7 & T16093C & 3.8 & T16325C & 3.8 \\
\hline T16311C $\mathrm{C}^{\star *}$ & 15.4 & C16261T & 7.7 & C16069T & 5.8 & A16163G & 3.8 & A16343G & 3.8 \\
\hline T16126C* & 11.5 & C16278T** & 7.7 & G16129A & 5.8 & C16186T & 3.8 & T16356C* & 3.8 \\
\hline C16292T** & 9.6 & C16294T & 7.7 & G16145A & 5.8 & T16209C & 3.8 & G16391A & 3.8 \\
\hline
\end{tabular}

T16063C, C16082T, T16086C, T16092C, C16142T, G16153A, C16176G, C16179T, A16183C**, C16184A, C16185T, C16193T** A16207C, C16218T $T^{* *}, C 16234 T, T 16249 C^{* *}, A 16254 G, C 16270 T^{* *}, C 16287 T, C 16291 T, A 16293 G *, A 16299 G, A 16318 T$, A16335G, C16354T and T16362C variations were detected in only one tumor (1.9\%). *: Reported to be GBM related (15), **: Reported in other cancer types (15).

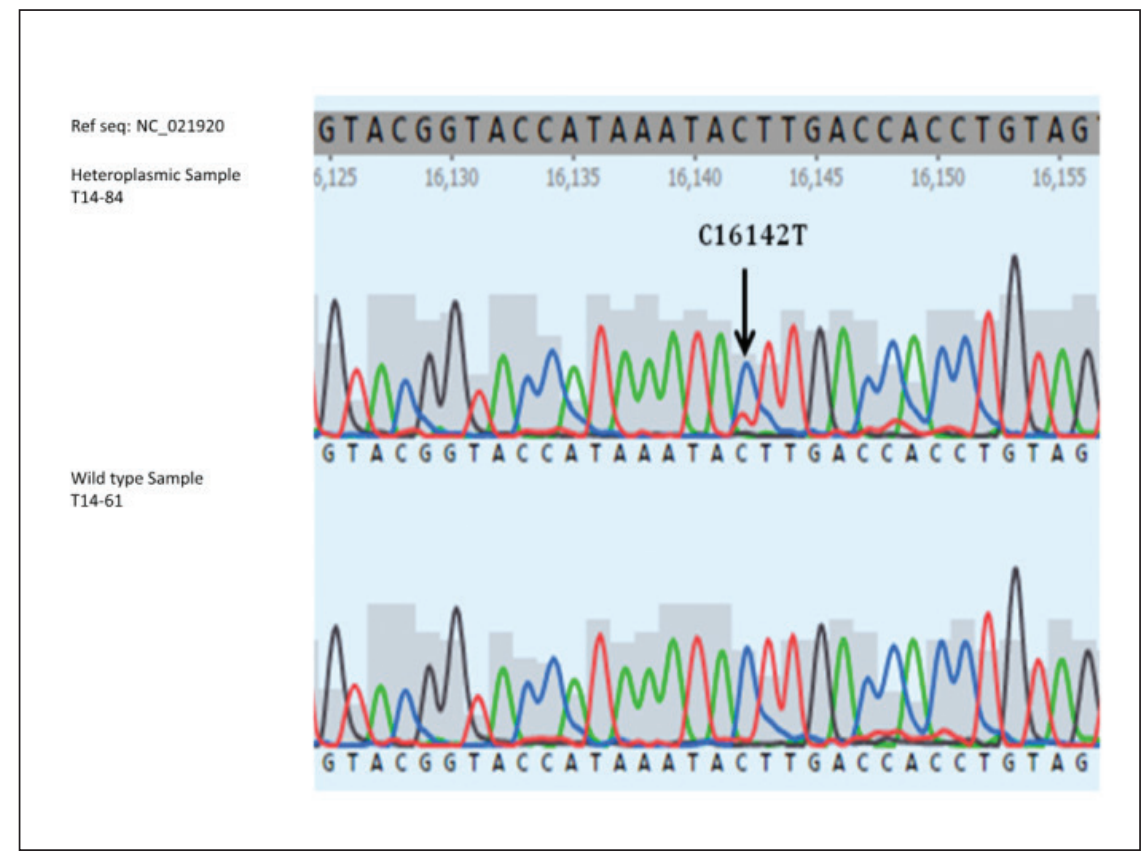

Figure 1: Sanger sequencing analysis of sample T14-84. The gray lane is the rCRS reference sequence (NC_021920). The black arrow on the electropherogram shows the heteroplasmic m.16142C $>$ T variation (upper lane) compared with homoplasmic wild type sample (T14-61, lower line).
1.82 in only IDH-mutant, $2.45 \pm 1.13$ in only TERT-mutant, $2.13 \pm 1.96$ in double-mutant and $2.86 \pm 2.12$ in double negative samples.

All the detected variations were homoplasmic except for the $\mathrm{m} .16142 \mathrm{C}>\mathrm{T}$ variation in a double-mutant WHO grade II female oligodendroglioma patient (DNA code: T14-84) (Figure 1). Nevertheless, 3 heteroplasmic variations were detected in the preliminary NGS analysis. m.16093T $>C$ and $\mathrm{m} .16278 \mathrm{C}>\mathrm{T}$ variations were found in IDH/TERT double-negative male, whereas m.16185C>T was present in only-TERT mutant female GBM patients.

The most frequent mutations (>10\%) that have been identified in the D-loop region were m.16223C > T (19.2\%), m.16189T>C (17.3\%), m.16311T $>C$ (15.4\%) and m.16126T>C (11.5\%). $92.5 \%$ of the detected variations were transitions $(C>T$ and $\mathrm{T}>\mathrm{C}$, being the most common).
Mann Whitney $U$ test was used for the comparison of total variation number of two groups for gender (female/male) ( $\mathrm{p}=0.185)$, IDH1 R132 mutation $(\mathrm{p}=0.319)$, morphological WHO grade II \& III vs IV ( $p=0.259)$ and WHO grade II vs III \& IV $(p=0.633)$. In addition, Kruskal-Wallis test was used for the comparison of more than two groups of morphological WHO grade II vs III vs IV $(p=0.518)$, WHO classification (oligodendroglioma, astrocytoma, GBM) $(\mathrm{p}=0.613)$ and IDH/ TERT status (only IDH-mutant, only TERT-mutant, doublemutant, double-negative) $(p=0.794)$. All of these comparisons were found to be statistically non-significant. However, when individual variants were evaluated using the Fisher's Exact test, m.16311T $>C$ was found to be statistically different among WHO classification $(\mathrm{p}=0.033)$ and morphological grade $(p=0.036)$, whereas $m .16224 T>C$ variant was only statistically significant among gender $(p=0.039)$. 


\section{DISCUSSION}

Mitochondria are important organelles involved in oxidative phosphorylation, production and detoxification of reactive oxygen species (ROS), heat production, apoptosis, $\mathrm{Ca}^{+2}$ regulation, lipid metabolism, steroid hormone and heme synthesis (19).

The mitochondrial DNA is thought to be susceptible to mutations due to the lack of histones, oxygen radicals in mitochondria that cause oxidative DNA damage, and poor fidelity of DNA polymerase gamma (2). Under increased oxidative stress conditions, the highly polymorphic D-loop region accumulates mutations at a higher frequency than other regions of mtDNA (8).

D-loop is $1124 \mathrm{bp}$ in size (16024-576 bp) and contains the three hypervariable regions, MT-HV1 (16024-16383 bp), MTHV2 (57-372 bp) and MT-HV3 (438-574 bp) (15). Promoters for both the heavy (HSP1 and HSP2) and light (LSP) strands and classical origin of heavy strand $\left(\mathrm{O}_{H}\right)$ are located in this region which is important in the initiation of transcription (5).

Although no genes are encoded in the D-loop control region, it plays a critical role in the regulation of mitochondrial transcription and replication. High frequency of variations was reported in this region, most (about 95\%) of them being transitions that are associated with oxidative DNA damage (11). These variations do not lead to growth disadvantage for the cell and have been associated with risk, survival, prognosis, and/or response to therapies in different cancer types (8).

Similar to nuclear mutational signature (7), mtDNA mutational signatures are reported to be very similar regardless of cancer tissue origins $(18,22)$. Consistent with literature $\mathrm{C}>\mathrm{T}$ transitions were the most commonly detected in our samples.

Sequencing analysis of D-loop region (15971-16451 bp) revealed a total of 122 variations, 51 being different. Mean total variation numbers were relatively high in IDH1 R132 wild type and IDH/TERT double negative samples and also WHO grade IV GBM patients. These results suggest that the mitochondrial variation number is high in more aggressive gliomas, which is in line with the literature $(8,10,11)$.

In the present study, we have identified homoplasmic variations in general, except for one heteroplasmic variation (m.16142C>T). This situation may be explained by the lower sensitivity (approximately $>10 \%$ ) of Sanger sequencing.

One of the commonly detected variations, m.16126T $>C$, which is a haplogroup marker, was reported in GBM (11). Other common variations m.16189T $>C, m .16223 C>T, m .16311 T>C$ were reported in different cancer types other than gliomas (15), and as polymorphisms in brain tumors $(11,16)$. m.16189T $>C$ variation results in a longer polycytosine tract $\left(\mathrm{C}_{5} \mathrm{TC}_{4}\right.$ resulting in $\mathrm{C}_{10}$ ), which may create a replication error-prone site (11).

Of the less frequently detected variants m.16293A>G (11), $\mathrm{m} .16325 \mathrm{~T}>\mathrm{C}(16)$ and $\mathrm{m} .16356 \mathrm{~T}>\mathrm{C}(11,16)$ were reported as somatic variations in gliomas. In addition, m.16069C $>\mathrm{T}$, $\mathrm{m} .16186 \mathrm{C}>\mathrm{T}$ and $\mathrm{m} .16362 \mathrm{~T}>\mathrm{C}$ alterations were shown to be significantly associated with histologically diagnosed brain tumors (3). On the other hand, m.16163A $>\mathrm{G}$ variation is located in the termination associated region and $\mathrm{m} .16093 \mathrm{~T}>\mathrm{C}$, m.16183A $>$ C, m.16193C $>\mathrm{T}, \quad \mathrm{m} .16218 \mathrm{C}>\mathrm{T}, \quad \mathrm{m} .16249 \mathrm{~T}>\mathrm{C}$, $\mathrm{m} .16270 \mathrm{C}>\mathrm{T}, \quad \mathrm{m} .16278 \mathrm{C}>\mathrm{T}, \mathrm{m} .16292 \mathrm{C}>\mathrm{T}, \mathrm{m} .16304 \mathrm{~T}>\mathrm{C}$, $\mathrm{m} .16390 \mathrm{G}>\mathrm{A}$ were reported in other cancer types such as breast, ovarian, colon or prostate (15).

In our study, the total number of variants in mtDNA D-loop region was not found to be related to clinicopathological parameters regarding the region 15971-16451, which does not cover the whole D-loop. Additionally, the number of GBM patients in our cohort, in terms of WHO classification, is low. However, these initial findings are important in the context of glioma biology and might pioneer further investigations. Since variations that are distributed in D-loop are reported to be frequently detected especially in GBM samples $(11,16)$ the analysis of more patients including the whole D-loop must be considered in order to deduce a conclusion about the significance of mitochondrial variations in glioma biology.

When individual variants were considered, m.16311T $>C$ and m.16224T>C were found to be statistically significant among WHO classification, morphological grade, and gender, respectively. Both of these variants were investigated in different cancer types and reported to be possibly related with prostate cancer (4).

\section{CONCLUSION}

These results provide an overview of the presence of mtDNA D-loop alterations in glioma patients. In addition to nuclear genome aberrations like IDH and TERT promoter mutations, some specific mitochondrial variations may also be considered as potential cancer biomarkers for the risk and progression of brain tumors.

In conclusion, our data suggests that the D-loop individual variants in mtDNA may play a critical role in glioma biology.

\section{ACKNOWLEDGEMENTS}

This work was supported by grant from Acibadem Mehmet Ali Aydinlar University ABAPKO Project number 2018/03/02.

\section{REFERENCES}

1. Akyerli CB, Yuksel S, Can O, Erson-Omay EZ, Oktay $Y$, Cosgun E, Ulgen E, Erdemgil Y, Sav A, von Deimling A, Gunel M, Yakicier MC, Pamir MN, Ozduman K: Use of telomerase promoter mutations to mark specific molecular subsets with reciprocal clinical behavior in IDH mutant and IDH wild-type diffuse gliomas. J Neurosurg 128(4):1102-1114, 2018

2. Alexeyev M, Shokolenko I, Wilson G, LeDoux S: The maintenance of mitochondrial DNA integrity-critical analysis and update. Cold Spring Harb Perspect Biol 5(5):a012641, 2013

3. Altafi D: Mitochondrial polymorphisms, in the D-Loop area, are associated with brain tumors. Cell J 21(3):350-356, 2019

4. Álvarez-Cubero MJ: Mitochondrial haplogroups and polymorphisms reveal no association with sporadic prostate cancer in a southern European population. PLoS One 7(7):e41201, 2012 
5. Anderson S, Bankier AT, Barrell BG, de Bruijn MH, Coulson AR, Drouin J, Eperon IC, Nierlich DP, Roe BA, Sanger F, Schreier PH, Smith AJ, Staden R, Young IG: Sequence and organization of the human mitochondrial genome. Nature 290(5806):457-465, 1981

6. Blein S, Bardel C, Danjean V, McGuffog L, Healey S, Barrowdale D, Lee A, Dennis J, Kuchenbaecker KB, Soucy P, Terry MB, Chung WK, Goldgar DE, Buys SS, Breast Cancer Family Registry, Janavicius R, Tihomirova L, Tung N, Dorfling CM, van Rensburg EJ, Neuhausen SL, Ding YC, Gerdes AM, Ejlertsen B, Nielsen FC, Hansen TV, Osorio A, Benitez J, Conejero RA, Segota E, Weitzel JN, Thelander M, Peterlongo P, Radice P, Pensotti V, Dolcetti R, Bonanni B, Peissel B, Zaffaroni D, Scuvera G, Manoukian S, Varesco L, Capone GL, Papi L, Ottini L, Yannoukakos D, Konstantopoulou I, Garber J, Hamann U, Donaldson A, Brady A, Brewer C, Foo C, Evans DG, Frost D, Eccles D, DEMBRACE, Douglas F, Cook J, Adlard J, Barwell J, Walker L, Izatt L, Side LE, Kennedy MJ, Tischkowitz M, Rogers MT, Porteous ME, Morrison PJ, Platte R, Eeles R, Davidson R, Hodgson S, Cole T, Godwin AK, Isaacs C, Claes K, De Leeneer K, Meindl A, Gehrig A, Wappenschmidt B, Sutter C, Engel C, Niederacher D, Steinemann D, Plendl H, Kast K, Rhiem K, Ditsch N, Arnold N, Varon-Mateeva R, Schmutzler RK, Preisler-Adams S, Markov NB, Wang-Gohrke S, de Pauw A, Lefol C, Lasset C, Leroux D, Rouleau E, Damiola F, GE GEMO Study Collaborators, Dreyfus H, Barjhoux L, Golmard L, Uhrhammer N, Bonadona V, Sornin V, Bignon YJ, Carter J, Van Le L, Piedmonte M, DiSilvestro PA, de la Hoya M, Caldes T, Nevanlinna $H$, Aittomäki K, Jager A, van den Ouweland AM, Kets CM, Aalfs $\mathrm{CM}$, van Leeuwen FE, Hogervorst FB, Meijers-Heijboer HE, HEBON, Oosterwijk JC, van Roozendaal KE, Rookus MA, Devilee P, van der Luijt RB, Olah E, Diez O, Teulé A, Lazaro C, Blanco I, Del Valle J, Jakubowska A, Sukiennicki G, Gronwald J, Lubinski J, Durda K, Jaworska-Bieniek K, Agnarsson BA, Maugard C, Amadori A, Montagna M, Teixeira MR, Spurdle AB, Foulkes W, Olswold C, Lindor NM, Pankratz VS, Szabo Cl, Lincoln A, Jacobs L, Corines M, Robson M, Vijai J, Berger A, Fink-Retter A, Singer CF, Rappaport C, Kaulich DG, Pfeiler G, Tea MK, Greene MH, Mai PL, Rennert G, Imyanitov EN, Mulligan AM, Glendon G, Andrulis IL, Tchatchou S, Toland AE, Pedersen IS, Thomassen M, Kruse TA, Jensen UB, Caligo MA, Friedman E, Zidan J, Laitman Y, Lindblom A, Melin B, Arver B, Loman N, Rosenquist R, Olopade OI, Nussbaum RL, Ramus SJ, Nathanson KL, Domchek SM, Rebbeck TR, Arun BK, Mitchell G, Karlan BY, Lester J, Orsulic S, Stoppa-Lyonnet D, Thomas G, Simard J, Couch FJ, Offit K, Easton DF, ChenevixTrench G, Antoniou AC, Mazoyer S, Phelan CM, Sinilnikova OM, Cox DG: An original phylogenetic approach identified mitochondrial haplogroup T1a1 as inversely associated with breast cancer risk in BRCA2 mutation carriers. Breast Cancer Res 17:61, 2015

7. COSMIC: Catalogue of Somatic Mutations in Cancer [database online]. London, UK: Wellcome Sanger Institute, 2004

8. Errichiello E, Venesio T: Mitochondrial DNA variations in tumors: Drivers or passengers? In: Seligmann $\mathrm{H}$ (ed), Mitochondrial DNA - New Insights. London, UK: IntechOpen, 2018
9. Giles RE, Blanc H, Cann HM, Wallace DC: Maternal inheritance of human mitochondrial DNA. Proc Natl Acad Sci USA 77(11):6715-6719, 1980

10. Hopkins JF, Sabelnykova VY, Weischenfeldt J, Simon R, Aguiar JA, Alkallas R, Heisler LE, Zhang J, Watson JD, Chua MLK, Fraser M, Favero F, Lawerenz C, Plass C, Sauter G, McPherson JD, van der Kwast T, Korbel J, Schlomm T, Bristow RG, Boutros PC: Mitochondrial mutations drive prostate cancer aggression. Nat Commun 8(1):656, 2017

11. Kirches E, Krause G, Warich-Kirches M, Weis S, Schneider T, Meyer-Puttlitz B, Mawrin C, Dietzmann K: High frequency of mitochondrial DNA mutations in glioblastoma multiforme identified by direct sequence comparison to blood samples. Int J Cancer 93(4):534-538, 2001

12. Levin BC, Cheng $H$, Reeder DJ: A human mitochondrial DNA standard reference material for quality control in forensic identification, medical diagnosis, and mutation detection. Genomics 55(2):135-146, 1999

13. Louis DN, Ohgaki H, Wiestler OD, Cavenee WK, Burger PC, Jouvet A, Scheithauer BW, Kleihues P: The 2007 WHO classification of tumours of the central nervous system. Acta Neuropathol 114(2):97-109, 2007

14. Louis DN, Perry A, Reifenberger G, von Deimling A, FigarellaBranger D, Cavenee WK, Ohgaki H, Wiestler OD, Kleihues P, Ellison DW: The 2016 World Health Organization classification of tumors of the central nervous system: A summary. Acta Neuropathol 131(6):803-820, 2016

15. MITOMAP: A Human Mitochondrial Genome Database [database online]. Center for Mitochondrial and Epigenomic Medicine at the Children's Hospital of Philadelphia (CHOP), 1996. Updated January 1, 2020

16. Mohamed Yusoff AA, Mohd Nasir KN, Haris K, Mohd Khair SZN, Abdul Ghani ARI, Idris Z, Abdullah JM: Detection of somatic mutations in the mitochondrial DNA control region D-loop in brain tumors: The first report in Malaysian patients. Oncol Lett 14(5):5179-5188, 2017

17. Stawski H, Bintz BJ, Burnside ES, Wilson M: Preparing Whole Genome Human Mitochondrial DNA Libraries for Next Generation Sequencing (NGS) Using Illumina Nextera XT. Poster presentation at the $65^{\text {th }}$ Annual American Academy of Forensic Sciences, Washington DC, USA, 2013

18. Stewart JB, Alaei-Mahabadi B, Sabarinathan R, Samuelsson T, Gorodkin J, Gustafsson CM, Larsson E: Simultaneous DNA and RNA mapping of somatic mitochondrial mutations across diverse human cancers. PLoS Genet 11(6):e1005333, 2015

19. Wallace DC: A mitochondrial paradigm of metabolic and degenerative diseases, aging, and cancer: A dawn for evolutionary medicine. Annu Rev Genet 39:359-407, 2005

20. Wallace DC: Mitochondria and cancer. Nat Rev Cancer 12(10):685-698, 2012

21. Wirsching HG, Weller M: The role of molecular diagnostics in the management of patients with gliomas. Curr Treat Options Oncol 17:51, 2016

22. Yuan Y, Ju YS, Kim Y, Li J, Wang Y, Yoon CJ, Yang Y, Martincorena I, Creighton CJ, Weinstein JN, Xu Y, Han L, Kim HL, Nakagawa H, Park K, Campbell PJ, Liang H; PCAWG Consortium: Comprehensive molecular characterization of mitochondrial genomes in human cancers. Nat Genet 52(3):342-352, 2020 